\title{
Comparative Genomic Insights Into the Biosynthesis and Regulation of Mycobacterial Siderophores
}

\author{
Wu Lia Junli He ${ }^{\mathrm{a}}$ Longxiang Xie Tian Chen Jianping Xie
}

Institute of Modern Biopharmaceuticals, State Key Laboratory Breeding Base of Eco-Enviroment and Bio-Resource of the Three Gorges Area, School of Life Sciences, Southwest University, Chongqing, China; aWu Li and Junli He contributed equally to this work

\section{Key Words}

Mycobacteria $\cdot$ Siderophore $\cdot$ Biosynthesis $•$ Anti-tuberculosis

\begin{abstract}
Iron is essential for nearly all biological events. Siderophores are indispensable for most organisms to obtain iron from iron-limiting milieus. This holds particularly true for pathogens such as the causative agent of tuberculosis -- Mycobacterium tuberculosis. The categories of mycobacterial siderophores, their biosynthesis and regulation are summarized here. The siderophore biosynthesis and regulation differences between the pathogenic and nonpathogenic mycobacteria are highlighted from comparative genomic perspective, with an aim to find clues for drug or drug target within siderophore metabolism.
\end{abstract}

Copyright (C) 2013 S. Karger AG, Basel

\section{Introduction}

Tuberculosis (TB) remains a major public health problem worldwide. According to the 2011 WHO Report [1], there were 8.8 million incidences of tuberculosis globally. The problem is exacerbated by the emergence of multidrug-resistant strains (MDR-TB) and extensively drug-resistant MTB (XDR-TB). New drug or vaccine targets are urgently needed.

Iron is essential for mycobacterial growth in vitro, and obtaining this essential element is a formidable challenge to all pathogenic mycobacteria grown in vivo. Hence, the ability to obtain iron from the host is critical for pathogen proliferation, pathogenesis and latency. However, host iron is sequestered by transferrins and lactoferrins, heme components, Fe-S 
clusters and ferritins [2]. Once infected, the host immediately primes immunoprotection mechanisms to adjust internal iron levels, such as synthesizing hepcidin [3] and siderocalin [4], to fight against pathogens $[5,6]$. The mystery of the hitherto most successful pathogen -- Mycobacterium tuberculosis (M. tuberculosis) -- might be its superb ability to obtain iron via its high affinity siderophores. Evidence for this possibility is the observation that the growth of siderophore-deficient mycobacteria is hampered severely within intracellular iron-limiting milieu [7, 8].

Much research has been performed with mycobacterial siderophores. As early as in 1945, mycobactin was the target of chemotherapy [9]. More recently, many researchers [10-13] have used siderophores as models of antibacterial/antituberculosis drugs, in the hope of obtaining effective anti-TB agents. Some agents developed in these studies do kill $M$. tuberculosis [14], and spurred intensive study.

\section{Categories of mycobacterial siderophores}

Siderophores are small molecular chelators produced by most microorganisms and are important for iron uptake and transportation. Siderophores have multiple structures, special receptors and are regulated by environmental iron levels [15]. The survival and pathogenesis of microbes is closely related to their siderophores. For example, pyoverdindeficient Pseudomonas aeruginosa mutants became avirulent when injected into burned mice [16]. Siderophores are also involved in the microbial response to oxidative stress [17, 18]. In addition, siderophores are essential for M. smegmatis biofilm formation during iron starvation [19].

The major mycobacterial siderophores include the extracellular carboxymycobactin and exochelin and the intracellular mycobactin. Carboxymycobactins have a shorter alkyl side chain which terminates in a methyl ester, which renders carboxymycobactins more polar and soluble than mycobactin. This facilitates the secretion of carboxymycobactins into the aqueous extracellular milieu to obtain iron from environmental sources, including the host. Exochelin, a low-molecular-weight polypeptide synthesized through a non-ribosomal pathway, consists of unusual peptide bonds that protect the molecule from peptidase hydrolysis. The three hydroxamate groups of exochelin form the rigid hexahedral $\mathrm{Fe}^{3+}$ chelating centre.

The siderophores of the pathogenic $M$. tuberculosis consist of carboxymycobactin and mycobactin [20,21], while saprophytic M. smegmatis produces mycobactin and extracellular carboxymycobactin and exochelin [9, 20, 22-24]. Exochelin MN, isolated from M. neoaurum culture broth, is a peptide with unusual $\beta$-hydroxyhistidine and $N$-methyl groups. The molecule utilizes the cis-hydroxamate motif, the $-\mathrm{OH}$ and the imidazole nitrogen of $\beta$-OHHis, to coordinate iron [25] and these groups release iron in a pH-dependent manner [26]. Exochelin MN can provide iron for the M. leprae, even though this siderophore is not found in this bacterium [27].

\section{Biosynthesis of the mycobacterial siderophores}

\section{Mycobactin}

Mycobactin is assembled by a series of polyketide synthase/nonribosomal peptide synthetases in M. tuberculosis [28]. Two gene clusters, ie, a 24 kb genetic fragment containing the $m b t-1$ gene cluster and the unlinked $m b t-2$ cluster are involved in mycobactin production (Table 1). The genes in the former cluster were designated as $m b t A-J$ and mediated the synthesis of the mycobactin core scaffold [28], while genes in the latter cluster were involved in the assembly of mycobactin side chains [29]. The genes in $m b t-2$ cluster were annotated as $m b t \mathrm{~K}, m b t \mathrm{~L}, m b t \mathrm{M}(f a d \mathrm{D} 33$ ), and $m b t \mathrm{~N}$ (fadE14) for $R v 1347 \mathrm{c}, R v 1344, R v 1345$, and $R v 1346$, respectively [29]. A systematic mutational analysis found that $m b t H$ is dispensable for the 
Li/He/Xie/Chen/Xie: Biosynthesis and Regulation of Mycobacterial Siderophores

Table 1. Mycobacterial genes, gene products and the putative functions involved in mycobactin biosynthesis

\begin{tabular}{|c|c|c|c|c|}
\hline $\begin{array}{l}\text { Gene } \\
\text { clusters }\end{array}$ & Rv. No. & Genes & $\begin{array}{l}\text { Gene } \\
\text { products }\end{array}$ & Putative functions \\
\hline \multirow{10}{*}{$m b t-1$} & Rv2384 & $m b t \mathrm{~A}$ & MbtA & salicyl-AMP ligase/salicyl-S-ArCP synthetase \\
\hline & Rv2383c & $m b t \mathrm{~B}$ & $\mathrm{MbtB}$ & $\begin{array}{l}\text { peptide synthetase, editing theacyl carrier protein } \\
\text { (ArCP) }\end{array}$ \\
\hline & Rv2382c & $m b t \mathrm{C}$ & MbtC & polyketide synthase \\
\hline & Rv2381c & $m b t \mathrm{D}$ & MbtD & polyketide synthase \\
\hline & Rv2380c & $m b t \mathrm{E}$ & MbtE & peptide synthetase \\
\hline & $\operatorname{Rv} 2379 c$ & $m b t \mathrm{~F}$ & $\mathrm{MbtF}$ & peptide synthetase \\
\hline & Rv2378c & $m b t \mathrm{G}$ & $\mathrm{MbtG}$ & acetyl hydroxylase \\
\hline & Rv2377c & $m b t \mathrm{H}$ & $\mathrm{MbtH}$ & stimulate amino acid adenylation steps [71] \\
\hline & Rv2386c & $m b t \mathrm{I}$ & MbtI & Isochorismate synthase/salicylate synthase \\
\hline & Rv2385 & $m b t]$ & MbtJ & acetyl hydroxylase \\
\hline \multirow{4}{*}{$m b t-2$} & Rv1347c & $m b t \mathrm{~K}$ & MbtK & GCN5 $N$ - acetyltransferase \\
\hline & $\operatorname{Rv} 1344$ & $m b t \mathrm{~L}$ & MbtL & acyl carrier protein \\
\hline & Rv1345 & $m b t \mathrm{M}$ & FadD33 & acyl- AMP ligase / acyl-CoA synthase \\
\hline & Rv1346 & $m b t \mathrm{~N}$ & FadE14 & acyl-ACP dehydrogenase [29] \\
\hline
\end{tabular}

M. smagmetis mycobactin production [30]. The orthologs of $m b t A, m b t B, m b t C, m b t D, m b t E$, $m b t F, m b t G$, and $m b t T$ ( $m b t B$ and $m b t T$ fused into a single gene in the M. tuberculosis) present in diverse phylogenetic groups and with similar orientation. Horizontal gene transfer of the whole or a part of the $m b t$ gene cluster did occur across large evolutionary families [30].

The reactions involved in the synthesis of mycobactin are shown in Fig. 1. The bifunctional enzyme MbtI mediates a sequential reaction, in which chorismic acid is firstly converted into isochorismate and then into salicylate (the initial precursor of mycobactin) $[31,32]$. MbtA, the salicyl-AMP ligase/salicyl-S-ArCP synthetase, activates and transfers the salicylate to the ACP(acyl carrier protein) site of MbtB to form salicyl-S-ACP(I). Then, Ser/Thr is linked into salicyl-S-ACP and converted into a phenyloxazoline ring [28](I). Subsequently, a lysine activated by peptide synthetase MbtE or MbtF(III) is attached to the peptide chain $[33,34]$. Then malonyl-CoA and acetyl-CoA are integrated into the lysine residue by polyketone synthase MbtC/D [7, 34](II). Another lysine activated by peptide synthase MbtE or MbtF (III) is added to this peptide chain [34]. When these amino acids are cyclized, the assemblage of core structure of mycobactin is complete (IV). Biosynthesis of the lipid side chain is as follows [29] (V): FadD33, the acetyl-CoA synthase homolog of mycobacterial acyl-AMP ligase [35, 36], activates the lipid molecules required for mycobactin biosynthesis. Acyl-ACP dehydrogenase FadE14 shares high level similarity with acyl-CoA dehydrogenases, which catalyze the dehydrogenation of acyl-CoA thioesters to the related trans-2-enoylCoA $[37,38]$, and dehydrogenates the ACP-tethered products and transforms them into $\alpha$, $\beta$-unsaturated lipid chain. Subsequently, the unsaturated lipid chains are directly transferred onto the $\varepsilon$-amino group of Z-Lys-OMe (abbreviation of benzyloxycarbonyl lysine methyl ester) of the mycobactin core by Rv1347c (MbtK, GCN5 $N$ - acetyltransferase). Finally, in the presence of NADPH and FAD, Lys-N6-hydroxylase [7], encoded by $m b t \mathrm{G}$, performs the final N6-hydroxylation step at $\varepsilon$-amino position exclusively (VI).

\section{Exochelin}

The knowledge of the siderophore exochelin mostly originated from the study of the M. smegmatis exochelin. More than ten genes participate in exochelin biosynthesis. So far, no genes highly homologous to $f x b \mathrm{~A}, f x b \mathrm{~B}, f x b \mathrm{C}$, orf 1 , orf $2, f x u \mathrm{~A}, f x u \mathrm{~B}$ and $f x u \mathrm{C}$ can be found in $M$. tuberculosis genome [18], whether $M$. tuberculosis produces exochelin remains to be determined. The genes $f x b \mathrm{~A}, f x b \mathrm{~B}$ and $f x b \mathrm{C}$ are required for exochelin biosynthesis $[18,39$, 40]. FxbB and FxbC are homologous to non-ribosomal peptide synthetases and share their common motifs [40]. FxbB and FxbC possess six activation modules, FxbB1, FxbB2, FxbC1, FxbC2, FxbC3 and FxbC4, each of which contains an ATP-binding motif, an ATPase motif and a pantetheine attachment motif [18]. Three epimerase domains within C-terminal motifs 
Fig. 1. Schematic representation of the synthesis of mycobactin in Mycobacterium tuberculosis. Abbreviations: "R" represents "H" or "OH"; " $\mathrm{R}$ '” represents "CnHn+1".

I<smiles>C=C(OC1C=C(C(=O)OC(C)C)C=CC1O)OC1C=CC(CCC)=C(C(=O)OC(C)=O)C1O</smiles>

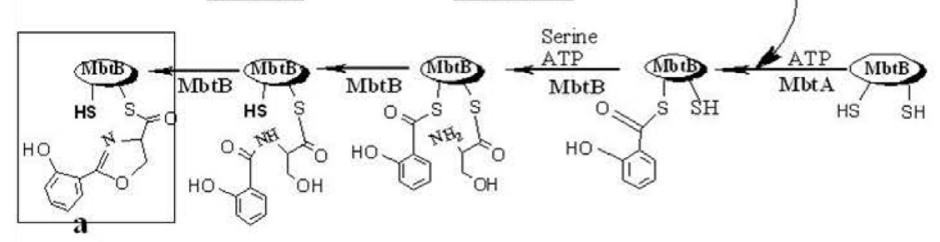

II

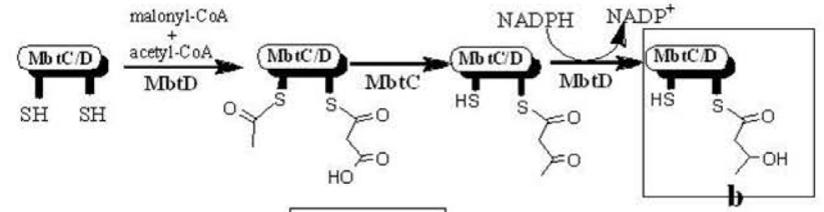

III

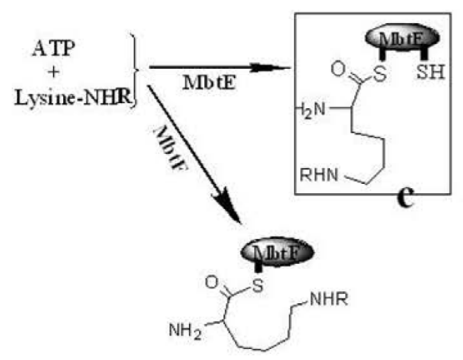

IV

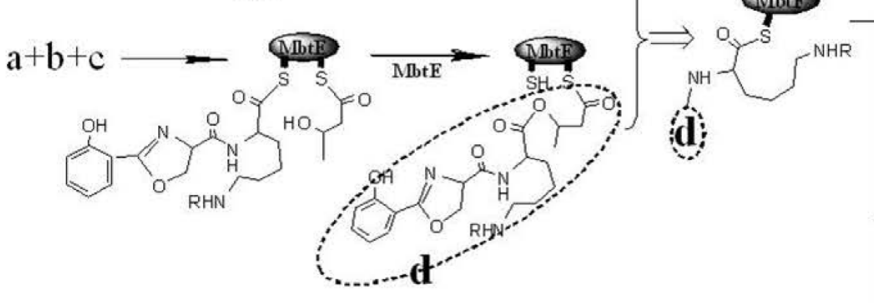

V
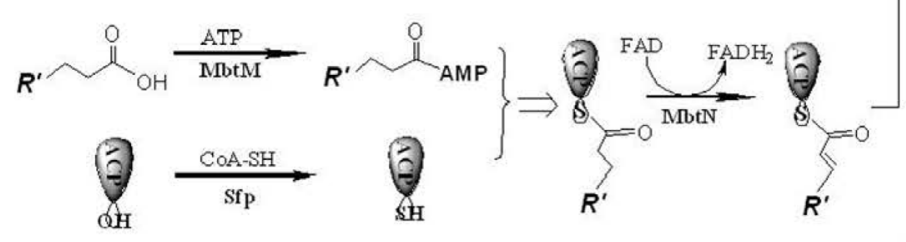

VI

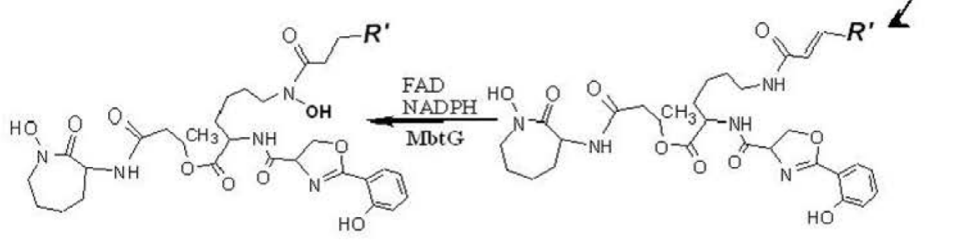

of FxbB1, FxbC1 and FxbC2 convert the $S$-amino acids to $R$-types [18]. Among other ORFs [18], ORF1, ORF2 and ORF3 share homology with the ABC transporters. ORF3 only contains a hydrophilic ATP-binding domain, while ORF1 and ORF2 have five and four hypothetic transmembrane domains in their N-terminal motifs apart from the ATP-binding cassettes. ORF4 and ORF5, with six and five transmembrane domains respectively, show homology to four putative membrane proteins of M. tuberculosis and M. leprae [18]. FxuD encoded by $f x u \mathrm{D}$ is a putative membrane-related receptor for ferric exochlin [18], while ExiT, a ABC transporter, is involved in the secretion of exochelin [40]. 
The exochelin is a linear formylated pentapeptide, which is organized with six unusual amino acids: one $\beta$-alanine, one $(R)$-allo-threonine, two $(R)-\delta$ - $N$-hydroxyornithines, one $(S)-\delta$ - $N$-hydroxyornithine and a formyl group. The $R$-amino acids in the siderophore are converted by three epimerase domains in FxbB and FxbC. The exochelin biosynthesis is proposed as following [18]: the FxbB1 and its C-terminal that contains a epimerase domain upload the first $(R)-\delta$ - $N$-hydroxyornithine, FxbB2 and FxbC3 (or FxbC4) may be responsible for attaching the $\beta$-alanine and the $(S)-\delta$ - $N$-hydroxyornithine to the backbone, the third and fourth $R$-amino acids , $(R)$ - $\delta$ - $N$-hydroxyornitheine and $(R)$-allo-threonine, are packed by the FxbC1 and FxbC2 and their C-terminal epimerase domains, the FxbA probably transfer a formyl group to the first $(R)-\delta$ - $N$-hydroxyornithine. The exochelin secreted by mycobacteria is a pentapeptide. The evolution of this molecule remains a mystery.

\section{Comparative genomic analysis of mycobacterial siderophore biosynthetic enzymes}

As Table 2 shows, fatty acyl synthetases responsible for side chain biosynthesis and similar functional enzymes exist in nearly all mycobacteria (except M. abscessus). Compared with the virulent M. tuberculosis H37Rv, the avirulent strain M. tuberculosis H37Ra has nearly all mycobactin/carboxymycobactin synthases with $99-100 \%$ identity, as is M. bovis AF2122/97. While the attenuated M.bovis BCG str. Pasteur 1173P2 lacks MbtI, MbtA and MbtG and the side-chain synthases also have low identity. This might underlie the attenuation of this BCG. M. smegmatis $\mathrm{MC}^{2} 155$, a fast-growing mycobacteria bearing all similar functional enzymes with identities between $30-80 \%$.

The widespread of these biosynthetic enzymes in nearly all pathogenic mycobacteria implicates that mycobactin might be involved in pathogenesis. The role of multiple MbtH and FadD33 in M. avium subsp. para K-10 remains to be determined and is suggestive of functions in addition to siderophore biosynthesis.

Non-pathogenic mycobacteria, Mycobacterium sp. JLS, Mycobacterium sp. KMS, Mycobacterium sp. MCS, M. vanbaalenii PYR-1 and M. gilvum PYR-GCK, have low, even no, identities of mycobactin core synthetases while the side-chain biosynthesis enzymes are conserved with identity between $60 \%$ and $80 \%$. However, they can utilize xenosiderophores by means of unknown mechanisms [41]. For example, M. leprae TN, incapable of producing mycobactin by itself, can usurp siderophores from other microbes, such as the M. neoaurum exochelin MN [25].

\section{Regulatory mechanisms of mycobacterial siderophore biosynthesis}

Mycobacterial siderophore biosynthesis is intensively regulated, largely by iron levels. Under low iron concentrations, siderophores are abundantly produced to obtain iron. The siderophore biosynthesis pathway is shut off in the presence of high iron. Four potential iron-dependent regulators have been found in M. tuberculosis [35]: FurA and FurB of the Fur family, IdeR and SirR of the DtxR family.

IdeR's role in mycobacterial iron metabolism is well documented and regulates about one third of iron-regulated genes [42]. IdeR, a pleiotropic regulator, plays a negative role in siderophore biosynthesis and modulates iron storage positively under high-iron conditions. It is also involved in the oxidative stress response, in both M. tuberculosis and M. smegmatis $[42,43]$. Similar to DtxR, the presence of ferrous iron will enable the metal-IdeR complex to bind to the regulatory region of $f x b \mathrm{~A}, m b t \mathrm{~A}-m b t \mathrm{~B}$ and $m b t \mathrm{I}$ to block their transcription $[44,45]$. Other divalent metals (Mn, Zn, Co) allow IdeR to bind to these regulatory regions, in biochemical experiments $[44,45]$. IdeR also binds to a $212 \mathrm{bp}$ sequence upstream of the Rv1348 transcription site [45], suggesting an effect on the siderophore transport. The iron metabolism-related genes regulated by IdeR are summarized in Table 3 [42].

In addition, Irep-28, the DNA-binding HU homologue HupB protein (hupB, Rv2986c) in the cell wall, has coordinated expression with siderophores mycobactin(s) and 
Cellular Physiology Cell Physiol Biochem 2013;31:1-13 and Biochemistry

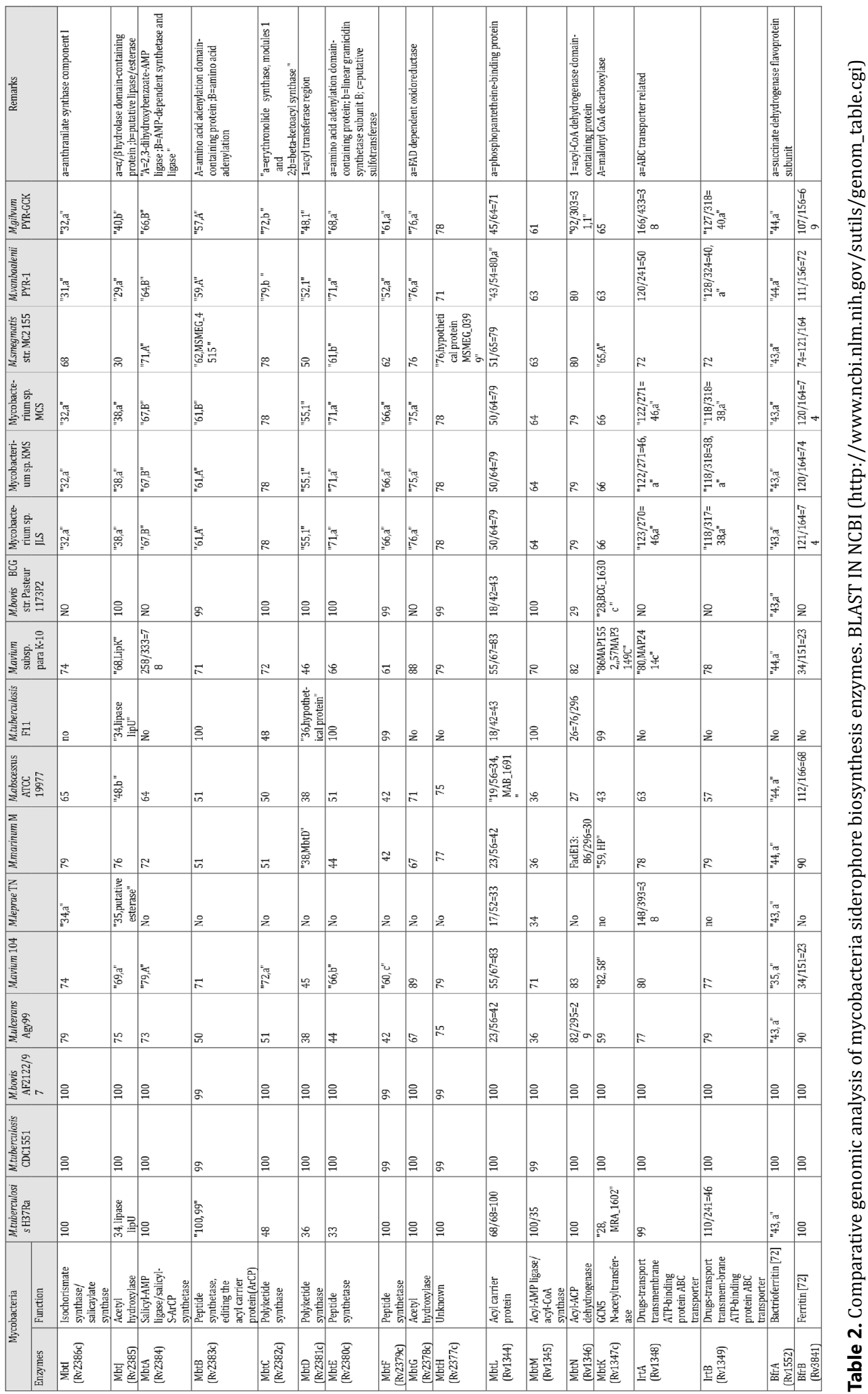


Li/He/Xie/Chen/Xie: Biosynthesis and Regulation of Mycobacterial Siderophores

\begin{tabular}{|c|c|c|c|c|}
\hline \multirow{2}{*}{$\begin{array}{l}\text { Table 3. IdeR } \\
\text { regulating iron }\end{array}$} & Rv no. & gene & gene products & regulation \\
\hline & 0288 & & CHP $^{b}$, ESAT-6 family & \multirow[t]{12}{*}{ inhibited by iron and IdeR } \\
\hline & 1345 & fadD33 & Acyl-CoA synthase & \\
\hline genes, & 1346 & fadE14 & Acyl-Co $\Lambda$ dehydrogenase & \\
\hline gene products & $1347 \mathrm{c}$ & $m b t \mathrm{~K}$ & IucB-like protein & \\
\hline and the regulation & 1348 & $\operatorname{irt} \mathrm{A}^{\mathrm{a}}$ & YbtP-like protein & \\
\hline to reference [55]; & $2377 \mathrm{c}$ & $m b t \mathrm{H}$ & Mycobactin synthesis & \\
\hline b, $\quad$ conserved & $2378 \mathrm{c}$ & $m b t \mathrm{G}$ & Lysine-N-oxygenase mycobactin synthesis & \\
\hline \multirow{22}{*}{$\begin{array}{l}\text { hy p ot h e t i c a l } \\
\text { protein. }\end{array}$} & $2379 c$ & $m b t \mathrm{~F}$ & Peptide synthase, mycobactin synthesis & \\
\hline & $2380 \mathrm{c}$ & $m b t \mathrm{E}$ & Peptide synthase, mycobactin synthesis & \\
\hline & $2381 \mathrm{c}$ & $m b t \mathrm{D}$ & Polyketide synthase, mycobactin synthesis & \\
\hline & 2385 & $\operatorname{lip} \mathrm{K}$ & Probable acetyl-hydrolase & \\
\hline & $2386 \mathrm{c}$ & $m b t \mathrm{I}(\operatorname{trp} \mathrm{E} 2)$ & Isochorismate synthase, mycobactin synthesis & \\
\hline & 1552 & $b f_{r} \mathrm{~A}$ & Bacterioferritin & \multirow[t]{4}{*}{ Iron- and IdeR-induced } \\
\hline & 3841 & $b f r \mathrm{~B}$ & Ferritin-like protein & \\
\hline & $0338 \mathrm{c}$ & & Fe-S protein & \\
\hline & 0009 & ppiA & peptide-prolyl-cis-trans isomerase & \\
\hline & 1463 & & Probable ABC transporter & \multirow{2}{*}{$\begin{array}{l}\text { Repressed by Iron but } \\
\text { IdeR-independent }\end{array}$} \\
\hline & $2794 c$ & & $\begin{array}{l}\mathrm{CH} \text {, similar to proteins involved in vibriobactin and } \\
\text { enterobactin synthesis }\end{array}$ & \\
\hline & 3145 & nuoA & NADH dehydrogenase chain A & \multirow{11}{*}{$\begin{array}{l}\text { Iron-induced but IdeR- } \\
\text { independent }\end{array}$} \\
\hline & 3146 & nuoB & NADH dehydrogenase chain B & \\
\hline & 3147 & nuoC & NADH dehydrogenase chain C & \\
\hline & 3148 & nuoD & NADH dehydrogenase chain $\mathrm{D}$ & \\
\hline & 3152 & nuoH & NADH dehydrogenase chain $\mathrm{H}$ & \\
\hline & 3153 & nuoI & NADH dehydrogenase chain I & \\
\hline & 3155 & nuoK & $\mathrm{NADH}$ dehydrogenase chain $\mathrm{K}$ & \\
\hline & 3156 & nuoL & NADH dehydrogenase chain $\mathrm{L}$ & \\
\hline & 3157 & nuo M & NADH dehydrogenase chain M & \\
\hline & 3158 & $n u o \mathrm{~N}$ & $\mathrm{~N} \Lambda \mathrm{DH}$ dehydrogenase chain $\mathrm{N}$ & \\
\hline & 3246 & $m t r A$ & Two-component response regulator & \\
\hline
\end{tabular}

carboxymycobactin(s), in response to iron level [46]. Seven IRPs (iron regulated proteins) identified by Calder and Horwitz [47] are regulated by iron concentrations: Irp15, Irp24 and Irp29 are upregulated in rich iron milieu, while Irp10, Irp13, Irp23 and Irp28 expression increased under iron deficiency. M. neoaurum mycobactin exochelin MN was expressed concomitantly with a 21-kDa envelope protein, and their levels are regulated by iron [48]: when iron is limited, both two components are expressed. When the iron is abundant, their levels are lowered. But the threshold of iron might vary with strains, medium and growth stages.

\section{Siderophore-mediated iron transport mechanism}

Microbial iron uptake process is largely as following: soluble siderophores are secreted to obtain environmental or host iron and are transformed into ferric siderophores. The ferrisiderophores are then transported into cells by the receptors located in the cell envelopes, and then iron ions are delivered to bacterioferritin to satisfy the physiological requirements. Both exochelins and carboxymycobactins can seize the extracellular iron and transfer the irons to the intracellular siderophores. However, as shown in Fig. 2, irons transport across the cell membranes are different. 
Fig. 2. Schematics of carboxymycobactin (A) and exochelin

iron transporting (A) pattern [8]. Extracellular d e s f e r r a t e d carboxymycobactins plunder the iron from host ironbinding proteins and convert to ferricarboxymycobactins. Then the carboxymycobactiniron complexes transferred iron to nonferrated mycobactins associated with the bacterium cell wall to form ferrated mycobactins. $\mathrm{Fe}^{3+}$ ions are transferred to cell membrane by ferrimycobactins, converted to $\mathrm{Fe}^{2+}$ by the reductases there and released into cytoplasm. At last, the excess irons could be stored or involved in

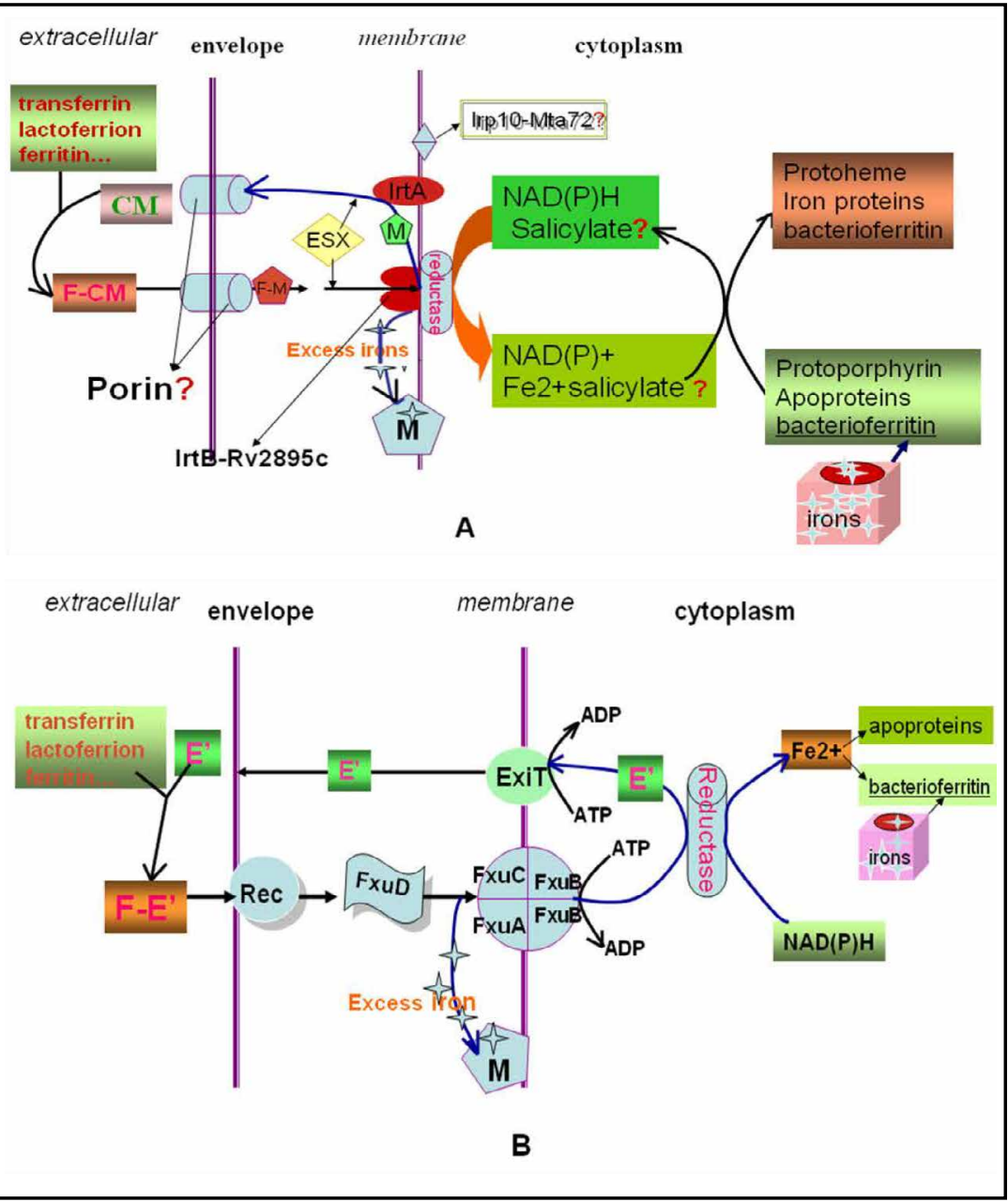
physiological process.

(B) Ferri-exochelins traverse the cell envelope, then pass through the tetramers which composed of one FxuA, two FxuB and one FxuC, and release the ferric ions into the cytoplasm. Subsequently, the desferrinexochelins are exported by ExiT proteins to chelate host iron. After being reduced in cytoplasm, the $\mathrm{Fe}^{2+}$ binds to various apoproteins and converts them to functional proteins, the excess iron ions would be saved in mycobactins transiently or stored in bacterioferrins. Abbreviations: CM, carboxymycobactin; E', exochelin; F, ferri; F-CM, ferri-carboxymycobactin; F-E', ferri-exochelin; M, mycobactin; ?, putative components involved in the transport.

The intracellular iron level is coordinated by salicylate and IdeR [49]. In iron-limited conditions, $M$. tuberculosis regulates the production of mycobactin and carboxymycobactin and carboxymycobactin secretion. As Fig. 2A shows, extracellular desferratedcarboxymycobactins can plunder the iron from the host iron-binding proteins, such as transferrins, lactoferrins and even the "iron storage" ferritins, and convert to ferricarboxymycobactins. Then the carboxymycobactin-iron complexes transferred iron to nonferrated mycobactins associated with the bacterium cell wall to form ferrated mycobactins [50]. $\mathrm{Fe}^{3+}$ ions are transferred to cell membrane by ferri-mycobactins, converted to $\mathrm{Fe}^{2+}$ by the reductases there and released into cytoplasm. With the help of cytoplasmic salicylate, iron is transferred into apoproteins and porphyrins to function or bacterioferritins to store [49], wherein over ninety percent of iron is stored [41]. IrtA facilitates the iron-unloaded mycobactins to back cell wall and recycle the iron trafficking [51]. In brief, mycobactins can cache excess iron, but the ultimate storages are bacterioferritins [41].

The iron transfer mediated by exochelins $[40,52]$ is illustrated in Fig. 2B: ferriexochelins are recognized by the specialized receptors in the cell wall and can traverse 
the cell envelope. Subsequently, the molecules pass the tetramers consisting of one FxuA, two FxuB and one FxuC, and release the ferric ions into the cytoplasm. Subsequently, the desferrated-exochelins are exported by ExiT proteins to chelate environmental iron. After being reduced in cytoplasm, the $\mathrm{Fe}^{2+}$ binds to various apoproteins and converts them to functional proteins, the excess iron ions would be saved in mycobactins transiently or stored in ferritins/bacterioferrins.

Although Gram-negative bacteria have various mechanisms for siderophore secretion and uptake across the outer membrane, analogous systems for penetrating the substantial cell wall of mycobacteria are poorly defined [53]. IrtA and IrtB, two putative ABC transporters located in cell membrane, are involved in the uptake of carboxymycbactin and that IrtA, which has a Flavin-Adenine Dinucleotide-binding domain and has putative Fe reductase activity, indicating IrtA functions to couple iron transport and assimilation [54, 55]. These two molecules interact and synergize to maintain the balance between iron and siderophores within mycobacterial cells [51]. And inactivation of the IrtAB system decreases the ability of M. tuberculosis to survive in mouse lung and macrophages [55]. Homology searches indicated that $M$. smegmatis genes namely msmeg_6554 and msmeg_6553 might be the counterparts of $M$. tuberculosis irtA and irtB, respectively [51]. Knockout of msmeg_6554 resulted in an impaired M. tuberculosis siderophore export that is restored upon complementation with $M$. tuberculosis irtA [51]. So Msmeg_6554 may be involved in siderophore secretion.

ESX-3 is a specialized secretion system required for mycobactin-mediated iron acquisition [56]. The ESX-3-deficient mycobacteria can synthesize mycobactin but incapable of utilizing the bound iron and are impaired severely for growth during macrophage infection [56]. Moreover, ESX-3 is regulated by the availability of iron and zinc, as part of the ideR and Fur (also known as Zur) regulons [42, 57].

In addition, the porins in the cell envelope of $M$. tuberculosis and two-component responsers Irep-Mta72 probably participate in the trafficking of iron [58, 59]. Porins played a role in the soluble iron acquisition under iron abundance and might affect the $M$. smegmatis siderophore production under iron deficiency [60]. Furthermore, investigators found that mycobacteria have taken advantage of endogenous macrophage mechanisms for iron mobilization and lipid sorting for iron acquisition during infection [61]. After bacteria infection, lipid droplets within human macrophage would concentrate into phagosomes and change the phagosomal contents $[62,63]$. Ironically, mycobacteria can benefit from this host defense mechanism to deliver iron during infection. This discovery suggests that mycobacteria can hijack macrophage inherent strategems to maintain their iron homeostasis [61].

\section{Future perspectives}

Significant advances on siderophore biosynthetic pathways and siderophore-mediated iron transport mechanism in different species of mycobacteria have revealed that iron acquisition, assimilation and regulation in M. tuberculosis play crucial role in proliferation, virulence and latency. Thus the components involved in this process are attractive target candidates for the development of inhibitors as potential new antibiotics for treating tuberculosis.

The relevance of mycobactin synthesis for pathogenic mycobacterial growth $[64,65]$ highlights the enzymes involved in siderophore production as potential target candidates for exploring the development of novel anti-tuberculosis. PAS or p-aminosalicylic acid, one of the earliest drugs to be used for tuberculosis treatment, is an analog of salicylic acid and inhibits the conversion of salicylate to mycobactin [49]. In an attempt to block siderophore synthesis, Qiao et al. [66] investigated the structure-activity relationship of 5'-0-[N-(salicyl) sulfamoyl]adenosine a potent inhibitor of the mycobactin biosynthetic enzyme MbtA (encoded by the gene Rv2384). The hydroxy group is essential for an optimal inhibitory activity via comparison of diverse derivatives. On the other hand, Somu et al. [67] have 
designed, synthesized, and evaluated a series of bisubstrate inhibitors of the adenylateforming enzyme MbtA involved in biosynthesis of mycobactins. An acylsulfamide was found to be potent inhibitor of $M$. tuberculosis growth under iron-limiting conditions.

IdeR is an essential regulator with a major role in controlling iron metabolism. The essential nature of IdeR makes it a potential candidate for therapeutic intervention against tuberculosis $[42,68]$. Moreover, investigating the role of IdeR-regulated genes in iron acquisition should provide additional potential targets for chemotherapy $[69,70]$. Targeting the M. tuberculosis specific iron transport and acquisition pathway involving ESX-3 or IrtA/ IrtB-Rv2895c could be another promising strategy to selectively block $M$. tuberculosis iron assimilation without impairing the host iron uptake machinery $[51,56]$.

Although great strides have been achieved as to siderophores, many remain to be explored. For instance, whether more secretion systems beyond ESX and IrtAB are involved in the siderophore utilization, siderophore-mediated iron acquisition needs some extracellular components to assist and what their function mechanisms are, for gram-positive bacteria, esp. M. tuberculosis, their impervious heavy waxy coats is a formidable barrier for novel antibiotics. Siderophore might be harnessed to chaperone or facilitate the administration of the antibiotics.

\section{Acknowledgements}

The authors thank Prof. Issar Smith (PHRI, UMDNJ, USA ) for the excellent and professional critical reading and revision of this manuscript. This work was funded by National megaprojects for key infectious diseases (No. 2008ZX10003-006, 2012ZX10003003), national natural science foundation(grant No. 81071316, No. 81271882), New century excellent talents in Universities (NCET-11-0703), Excellent PhD thesis fellowship of southwest university (Grant No. ky2011003), the Fundamental Research Funds for the Central Universities (Grant No. XDJK2012D011, XDJK2013D003, XDJK2012D007, Natural Science Foundation Project of CQ CSTC (Grant No. CSTC, 2010BB5002 ).

\section{References}

1 Organization WH: Global tuberculosis control: surveillance, planning, financing. WHO Report World Health Organization, Geneva, Switzerland 2011.

$>2$ Ratledge C, Dover LG: Iron metabolism in pathogenic bacteria. Annu Rev Microbiol 2000;54:881-941.

-3 Krause A, Neitz S, Magert HJ, Schulz A, Forssmann WG, Schulz-Knappe P, Adermann K: LEAP-1, a novel highly disulfide-bonded human peptide, exhibits antimicrobial activity. FEBS Lett 2000;480:147-150.

4 Kjeldsen L, Johnsen AH, Sengelov H, Borregaard N: Isolation and primary structure of NGAL, a novel protein associated with human neutrophil gelatinase. J Biol Chem 1993;268:10425-10432.

Doherty CP: Host-pathogen interactions: the role of iron. J Nutr 2007;137:1341-1344.

Schaible UE, Kaufmann SH: Iron and microbial infection. Nat Rev Microbiol 2004;2:946-953.

De Voss JJ, Rutter K, Schroeder BG, Barry CE, 3rd: Iron acquisition and metabolism by mycobacteria. J

Bacteriol 1999;181:4443-4451.

Ratledge C: Iron, mycobacteria and tuberculosis. Tuberculosis (Edinb) 2004;84:110-130.

Snow GA: Mycobactins: iron-chelating growth factors from mycobacteria. Bacteriol Rev 1970;34:99-125.

Neres J, Labello NP, Somu RV, Boshoff HI, Wilson DJ, Vannada J, Chen L, Barry CE, 3rd, Bennett EM, Aldrich CC: Inhibition of siderophore biosynthesis in Mycobacterium tuberculosis with nucleoside bisubstrate analogues: structure-activity relationships of the nucleobase domain of 5'-O-[N-(salicyl)sulfamoyl] adenosine. J Med Chem 2008;51:5349-5370.

11 Somu RV, Wilson DJ, Bennett EM, Boshoff HI, Celia L, Beck BJ, Barry CE, 3rd, Aldrich CC: Antitubercular nucleosides that inhibit siderophore biosynthesis: SAR of the glycosyl domain. J Med Chem 2006;49:76237635 . 
Li/He/Xie/Chen/Xie: Biosynthesis and Regulation of Mycobacterial Siderophores

12 Vannada J, Bennett EM, Wilson DJ, Boshoff HI, Barry CE, 3rd, Aldrich CC: Design, synthesis, and biological evaluation of beta-ketosulfonamide adenylation inhibitors as potential antitubercular agents. Org Lett 2006;8:4707-4710.

13 Manos-Turvey A, Bulloch EMM, Rutledge PJ, Baker EN, Lott JS, Payne RJ: Inhibition Studies of Mycobacterium tuberculosis Salicylate Synthase (MbtI). ChemMedChem 2010;5:1067-1079.

14 Stirrett KL, Ferreras JA, Jayaprakash V, Sinha BN, Ren T, Quadri LE: Small molecules with structural similarities to siderophores as novel antimicrobials against Mycobacterium tuberculosis and Yersinia pestis. Bioorg Med Chem Lett 2008;18:2662-2668.

15 Lewin R: How Microorganisms Transport Iron: In the midst of plenty, microorganisms are often in danger of iron-starvation; the mechanism by which they transport iron has now been elucidated. Science 1984;225:401-402.

16 Meyer JM, Neely A, Stintzi A, Georges C, Holder IA: Pyoverdin is essential for virulence of Pseudomonas aeruginosa. Infect Immun 1996;64:518-523.

17 Lundrigan MD, Arceneaux JE, Zhu W, Byers BR: Enhanced hydrogen peroxide sensitivity and altered stress protein expression in iron-starved Mycobacterium smegmatis. Biometals 1997;10:215-225.

18 Yu S, Fiss E, Jacobs WR Jr: Analysis of the exochelin locus in Mycobacterium smegmatis: biosynthesis genes have homology with genes of the peptide synthetase family. J Bacteriol 1998;180:4676-4685.

19 Ojha A, Hatfull GF: The role of iron in Mycobacterium smegmatis biofilm formation: the exochelin siderophore is essential in limiting iron conditions for biofilm formation but not for planktonic growth. Mol Microbiol 2007;66:468-483.

-20 Gobin J, Moore CH, Reeve JR Jr, Wong DK, Gibson BW, Horwitz MA: Iron acquisition by Mycobacterium tuberculosis: isolation and characterization of a family of iron-binding exochelins. Proc Natl Acad Sci U S A 1995;92:5189-5193.

-21 Snow GA: Isolation and structure of mycobactin T, a growth factor from Mycobacterium tuberculosis. Biochem J 1965;97:166-175.

22 Ratledge C, Ewing M: The occurrence of carboxymycobactin, the siderophore of pathogenic mycobacteria, as a second extracellular siderophore in Mycobacterium smegmatis. Microbiology 1996;142:2207-2212.

-23 Sharman GJ, Williams DH, Ewing DF, Ratledge C: Isolation, purification and structure of exochelin MS, the extracellular siderophore from Mycobacterium smegmatis. Biochem J 1995;305:187-196.

24 Lane SJ, Marshall PS, Upton RJ: Novel Extracellular Mycobactins, the Carboxymycobactins from Mycobacterium avium. Tetrahedron Letters 1995;36:4129-4132.

-25 Sharman GJ, Williams DH, Ewing DF, Ratledge C: Determination of the structure of exochelin MN, the extracellular siderophore from Mycobacterium neoaurum. Chem Biol 1995;2:553-561.

-26 Dong L, Miller MJ, Mollmann U: Microbial growth promotion studies of exochelin MN and analogues thereof. Biometals 2004;17:99-104.

-27 Hall RM, Ratledge C: Exochelin-mediated iron acquisition by the leprosy bacillus, Mycobacterium leprae. J Gen Microbiol 1987;133:193-199.

28 Quadri LE, Sello J, Keating TA, Weinreb PH, Walsh CT: Identification of a Mycobacterium tuberculosis gene cluster encoding the biosynthetic enzymes for assembly of the virulence-conferring siderophore mycobactin. Chem Biol 1998;5:631-645.

29 Krithika R, Marathe U, Saxena P, Ansari MZ, Mohanty D, Gokhale RS: A genetic locus required for iron acquisition in Mycobacterium tuberculosis. Proc Natl Acad Sci USA 2006;103:2069-2074.

30 Chavadi SS, Stirrett KL, Edupuganti UR, Vergnolle O, Sadhanandan G, Marchiano E, Martin C, Qiu WG, Soll CE, Quadri LE: Mutational and phylogenetic analyses of the mycobacterial mbt gene cluster. J Bacteriol 2011;193:5905-5913.

- 31 Harrison AJ, Ramsay RJ, Baker EN, Lott JS: Crystallization and preliminary X-ray crystallographic analysis of MbtI, a protein essential for siderophore biosynthesis in Mycobacterium tuberculosis. Acta Crystallogr Sect F Struct Biol Cryst Commun 2005;61:121-123.

- 32 Harrison AJ, Yu M, Gardenborg T, Middleditch M, Ramsay RJ, Baker EN, Lott JS: The structure of MbtI from Mycobacterium tuberculosis, the first enzyme in the biosynthesis of the siderophore mycobactin, reveals it to be a salicylate synthase. J Bacteriol 2006;188:6081-6091.

-33 LaMarca BB, Zhu W, Arceneaux JE, Byers BR, Lundrigan MD: Participation of fad and mbt genes in synthesis of mycobactin in Mycobacterium smegmatis. J Bacteriol 2004;186:374-382. 
$\mathrm{Li} / \mathrm{He} / \mathrm{Xie} / \mathrm{Chen} / \mathrm{Xie}$ B Biosynthesis and Regulation of Mycobacterial Siderophores

34 Crosa JH, Walsh CT: Genetics and assembly line enzymology of siderophore biosynthesis in bacteria. Microbiol Mol Biol Rev 2002;66:223-249.

-35 Cole ST, Brosch R, Parkhill J, Garnier T, Churcher C, Harris D, Gordon SV, Eiglmeier K, Gas S, Barry CE, 3rd, Tekaia F, Badcock K, Basham D, Brown D, Chillingworth T, Connor R, Davies R, Devlin K, Feltwell T, Gentles S, Hamlin N, Holroyd S, Hornsby T, Jagels K, Krogh A, McLean J, Moule S, Murphy L, Oliver K, Osborne J, Quail MA, Rajandream MA, Rogers J, Rutter S, Seeger K, Skelton J, Squares R, Squares S, Sulston JE, Taylor K, Whitehead S, Barrell BG: Deciphering the biology of Mycobacterium tuberculosis from the complete genome sequence. Nature 1998;393:537-544.

-36 Trivedi OA, Arora P, Sridharan V, Tickoo R, Mohanty D, Gokhale RS: Enzymic activation and transfer of fatty acids as acyl-adenylates in mycobacteria. Nature 2004;428:441-445.

-37 Ghisla S, Thorpe C: Acyl-CoA dehydrogenases. A mechanistic overview. Eur J Biochem 2004, 271:494-508.

-38 Kim JJ, Miura R: Acyl-CoA dehydrogenases and acyl-CoA oxidases. Structural basis for mechanistic similarities and differences. Eur J Biochem 2004;271:483-493.

-39 Fiss EH, Yu S, Jacobs WR Jr: Identification of genes involved in the sequestration of iron in mycobacteria: the ferric exochelin biosynthetic and uptake pathways. Mol Microbiol 1994;14:557-569.

-40 Zhu W, Arceneaux JE, Beggs ML, Byers BR, Eisenach KD, Lundrigan MD: Exochelin genes in Mycobacterium smegmatis: identification of an $\mathrm{ABC}$ transporter and two non-ribosomal peptide synthetase genes. Mol Microbiol 1998;29:629-639.

41 Matzanke BF, Bohnke R, Mollmann U, Reissbrodt R, Schunemann V, Trautwein AX: Iron uptake and intracellular metal transfer in mycobacteria mediated by xenosiderophores. Biometals 1997;10:193-203.

42 Rodriguez GM, Voskuil MI, Gold B, Schoolnik GK, Smith I: ideR, An essential gene in mycobacterium tuberculosis: role of IdeR in iron-dependent gene expression, iron metabolism, and oxidative stress response. Infect Immun 2002;70:3371-3381.

-43 Dussurget 0, Rodriguez M, Smith I: An ideR mutant of Mycobacterium smegmatis has derepressed siderophore production and an altered oxidative-stress response. Mol Microbiol 1996;22:535-544.

-44 Dussurget 0, Timm J, Gomez M, Gold B, Yu S, Sabol SZ, Holmes RK, Jacobs WR Jr, Smith I: Transcriptional control of the iron-responsive fxbA gene by the mycobacterial regulator IdeR. J Bacteriol 1999;181:34023408.

45 Gold B, Rodriguez GM, Marras SA, Pentecost M, Smith I: The Mycobacterium tuberculosis IdeR is a dual functional regulator that controls transcription of genes involved in iron acquisition, iron storage and survival in macrophages. Mol Microbiol 2001;42:851-865.

-46 Yeruva VC, Duggirala S, Lakshmi V, Kolarich D, Altmann F, Sritharan M: Identification and characterization of a major cell wall-associated iron-regulated envelope protein (Irep-28) in Mycobacterium tuberculosis. Clin Vaccine Immunol 2006;13:1137-1142.

47 Calder KM, Horwitz MA: Identification of iron-regulated proteins of Mycobacterium tuberculosis and cloning of tandem genes encoding a low iron-induced protein and a metal transporting ATPase with similarities to two-component metal transport systems. Microbial Pathogenesis 1998;24:133-143.

48 Sritharan M, Ratledge C: Co-ordinated expression of the components of iron transport (mycobactin, exochelin and envelope proteins) in Mycobacterium neoaurum. FEMS Microbiol Lett 1989;51:183-185.

-49 Adilakshmi T, Ayling PD, Ratledge C: Mutational analysis of a role for salicylic acid in iron metabolism of Mycobacterium smegmatis. J Bacteriol 2000;182:264-271.

50 Gobin J, Horwitz MA: Exochelins of Mycobacterium tuberculosis remove iron from human iron-binding proteins and donate iron to mycobactins in the M. tuberculosis cell wall. J Exp Med 1996;183:1527-1532.

51 Farhana A, Kumar S, Rathore SS, Ghosh PC, Ehtesham NZ, Tyagi AK, Hasnain SE: Mechanistic insights into a novel exporter-importer system of Mycobacterium tuberculosis unravel its role in trafficking of iron. PLoS One 2008; 3:e2087.

52 Hall RM, Sritharan M, Messenger AJ, Ratledge C: Iron transport in Mycobacterium smegmatis: occurrence of iron-regulated envelope proteins as potential receptors for iron uptake. J Gen Microbiol 1987;133:21072114.

53 Miethke M, Marahiel MA: Siderophore-based iron acquisition and pathogen control. Microbiol Mol Biol Rev 2007;71:413-451.

54 Ryndak MB, Wang S, Smith I, Rodriguez GM: The Mycobacterium tuberculosis high-affinity iron importer, IrtA, contains an FAD-binding domain. J Bacteriol 2010;192:861-869. 
Li/He/Xie/Chen/Xie: Biosynthesis and Regulation of Mycobacterial Siderophores

55 Rodriguez GM, Smith I: Identification of an $\mathrm{ABC}$ transporter required for iron acquisition and virulence in Mycobacterium tuberculosis. J Bacteriol 2006;188:424-430.

56 Siegrist MS, Unnikrishnan M, McConnell MJ, Borowsky M, Cheng TY, Siddiqi N, Fortune SM, Moody DB, Rubin EJ: Mycobacterial Esx-3 is required for mycobactin-mediated iron acquisition. Proc Natl Acad Sci USA 2009;106:18792-18797.

57 Maciag A, Dainese E, Rodriguez GM, Milano A, Provvedi R, Pasca MR, Smith I, Palu G, Riccardi G, Manganelli R: Global analysis of the Mycobacterium tuberculosis Zur (FurB) regulon. J Bacteriol 2007;189:730-740.

58 Calder KM, Horwitz MA: Identification of iron-regulated proteins of Mycobacterium tuberculosis and cloning of tandem genes encoding a low iron-induced protein and a metal transporting ATPase with similarities to two-component metal transport systems. Microb Pathog 1998;24:133-143.

59 Kartmann B, Stenger S, Niederweis M: Porins in the cell wall of Mycobacterium tuberculosis. J Bacteriol 1999;181:6543-6546.

60 Jones CM NM: Role of Porins in Iron Uptake by Mycobacterium smegmatis. J Bacteriol 2010;192:64116417.

61 Luo M, Fadeev EA, Groves JT: Mycobactin-mediated iron acquisition within macrophages. Nat Chem Biol 2005;1:149-153.

62 Dvorak AM: Lipid bodies: cytoplasmic organelles important to arachidonate metabolism in macrophages and mast cells. J Immunol 1983;131:2965-2976.

63 Murphy DJ: The biogenesis and functions of lipid bodies in animals, plants and microorganisms. Lipid Res 2001;40:325-438.

64 De Voss JJ, Rutter K, Schroeder BG, Su H, Zhu Y, Barry CE $3^{\text {rd: }}$ The salicylate-derived mycobactin siderophores of Mycobacterium tuberculosis are essential for growth in macrophages. Proc Natl Acad Sci USA 2000;97:1252-1257.

-65 Tullius MV, Harth G, Maslesa-Galic S, Dillon BJ, Horwitz MA: A Replication-Limited Recombinant Mycobacterium bovis BCG vaccine against tuberculosis designed for human immunodeficiency viruspositive persons is safer and more efficacious than BCG. Infect Immun 2008;76:5200-5214.

66 Qiao C, Gupte A, Boshoff HI, Wilson DJ, Bennett EM, Somu RV, Barry CE, 3rd, Aldrich CC: 5'-O-[(N-acyl) sulfamoyl]adenosines as antitubercular agents that inhibit MbtA: an adenylation enzyme required for siderophore biosynthesis of the mycobactins. J Med Chem 2007;50:6080-6094.

67 Somu RV, Boshoff H, Qiao C, Bennett EM, Barry CE, 3rd, Aldrich CC: Rationally designed nucleoside antibiotics that inhibit siderophore biosynthesis of Mycobacterium tuberculosis. J Med Chem 2006;49:3134.

68 Prakash P, Yellaboina S, Ranjan A, Hasnain SE: Computational prediction and experimental verification of novel IdeR binding sites in the upstream sequences of Mycobacterium tuberculosis open reading frames. Bioinformatics 2005;21:2161-2166.

69 Domenech P, Reed MB, Barry CE $3^{\text {rd }}$ : Contribution of the Mycobacterium tuberculosis MmpL protein family to virulence and drug resistance. Infect Immun 2005;73:3492-3501.

70 Ren J, Prescott JF: Analysis of virulence plasmid gene expression of intra-macrophage and in vitro grown Rhodococcus equi ATCC 33701. Vet Microbiol 2003;94:167-182.

-71 Felnagle EA, Barkei JJ, Park H, Podevels AM, McMahon MD, Drott DW, Thomas MG: MbtH-like proteins as integral components of bacterial nonribosomal peptide synthetases. Biochemistry 2010;49:8815-8817.

72 Pandey R, Rodriguez GM: A ferritin mutant of Mycobacterium tuberculosis is highly susceptible to killing by antibiotics and is unable to establish a chronic infection in mice. Infect Immun 2012;80:3650-3659. 